\title{
Positional Variation in Pedal Unguals of North American Ornithomimids (Dinosauria, Theropoda): A Response to Brownstein (2017)
}

\author{
Bradley McFeeters ${ }^{1 \star}$, Michael J. Ryan ${ }^{1,2}$, and Thomas M. Cullen ${ }^{3}$
}

${ }^{1}$ Dept. Earth Sciences, Carleton University, Ottawa, Ontario, K1S 5B6, Canada; bradleymcfeeters@cmail.carleton.ca ${ }^{2}$ Cleveland Museum of Natural History, 1 Wade Oval Drive, Cleveland, Ohio 41106-1767, USA; mryan@cmnh.org ${ }^{3}$ Field Museum of Natural History, 1400 S Lake Shore Drive, Chicago, Illinois 60605, USA; thomas.cullen@ fieldmuseum.org

\begin{abstract}
Positional variation is documented in ornithomimid pedal unguals from the Dinosaur Park and Horseshoe Canyon Formations of Alberta, Canada, and characters for identifying the position of isolated ornithomimid pedal unguals are discussed. Ungual morphology has been used recently to argue for the coexistence of two distinct ornithomimosaurs, a basal taxon and distinctly more derived taxon, in the Early Cretaceous Arundel Clay of Maryland, USA. However, these conclusions are based on misconceptions of the morphology and positional variability of ornithomimosaur unguals. Some characters previously cited as diagnostic of ornithomimosaur unguals are not actually observed in this clade, or are more homoplastically distributed among theropods. Other characters proposed to distinguish between the two pedal ungual morphs in the Arundel Clay material are shown in the Albertan ornithomimid material to consistently distinguish the different ungual positions within the pes of one individual. Claims of multiple distinct ornithomimosaur taxa in the Arundel Clay are premature, as the two pedal ungual morphotypes more likely represent positional variation in a single taxon.
\end{abstract}

\section{INTRODUCTION}

The ornithomimosaur pes is regarded as an important source of taxonomically informative anatomical information, with several recently named species diagnosed almost exclusively by pedal characters (Serrano-Brañas et al. 2016; Tsogtbaatar et al. 2017; Hunt and Quinn 2018). Most pedal phalanges have distinct morphologies that permit assignment of disarticulated and even isolated elements to their correct position in the pes (e.g., McFeeters et al. 2016:fig. 11). However, the anatomical differences (here referred to as 'positional variation') that distinguish the individual pedal unguals have not been widely appreciated, owing to the relative rarity of ornithomimid specimens that have all three pedal unguals adequately represented, as well as the inaccessibility of some aspects of ungual anatomy in articulated or mounted individuals.

Published accounts of positional variation in ornithomimosaur pedal unguals are limited in number. One of the few exceptions is Tsogtbaatar et al. (2017), in which pos-

*corresponding author

Published May 24, 2018

(c) 2018 by the authors

submitted April 25, 2017; revisions received May 3, 2018; accepted May 5, 2018. Handling editor: Robert Holmes. itional variation in a complete set of unguals from a single pes of the ornithomimid Aepyornithomimus tugrikinensis was described and figured. Barsbold and Osmólska (1990) and Makovicky et al. (2004), in their classic overviews of ornithomimosaur anatomy, characterized the morphology of the pedal unguals only in general terms, without discussing positional variation. Sereno (2017) identified the single known pedal ungual of a potential basal ornithomimosaur, Afromimus tenerensis, as a right pedal ungual II on the basis of its asymmetry, associated pedal elements, and comparisons to the unguals of a reportedly complete pes of the ornithomimid Sinornithomimus dongi. However, as the latter specimen has yet to be figured, this comparison is difficult to evaluate. Hunt and Quinn (2018) noted positional variation in the incompletely preserved pedal unguals of the basal ornithomimosaur Arkansaurus fridayi, but were unable to assign each ungual to a digit. Longrich (2008) described some isolated ornithomimosaur unguals, but did not assign them to a particular digit. Cullen et al. (2013) described variation in associated ornithomimid unguals with reference to inferred position, and found some of the taxonomic characters used by Longrich (2008) to be problematic; however, the unguals described by Cullen et al. (2013) were not figured exhaustively, and no rationale for their positional identification was given. 
Although ornithomimosaurs are well represented in Campanian-Maastrichtian deposits of the Western Interior of North America, they are rare in older and more eastern localities on this continent (Makovicky et al. 2004) where most reports are based on isolated elements (e.g., Schwimmer et al. 2015; Brownstein 2017). Recently, Brownstein (2017) described six isolated ungual phalanges from the Aptian-aged Arundel Clay facies (Potomac Formation) in Maryland, USA, which he regarded as the primary evidence for the existence of two distinct, co-occurring ornithomimosaur taxa in this fossil assemblage (Brownstein 2017, 2018). He further suggested that one of these taxa might share a more recent common ancestry with derived ornithomimosaurs such as ornithomimids, than with the other, supposedly more basal ornithomimosaur taxon. Brownstein's interpretation, if correct, has important implications for reconstructing the palaeobiogeographic history of ornithomimosaurs. However, the evidence used to support this conclusion is problematic, being based largely on misconceptions of the morphology and positional variability of ornithomimosaur unguals. In this paper, we re-examine the anatomy of ornithomimosaur pedal unguals from Alberta (including material previously described in Cullen et al. 2013) with special attention to positional variation among associated elements in an attempt to address this issue.

\section{ABBREVIATIONS}

Institutional abbreviations: $\mathrm{AMNH}$, American Museum of Natural History, New York City, New York, USA; CMN, Canadian Museum of Nature, Ottawa, Ontario, Canada; NHRD-AP, National and Historical Resources Division Archaeology Program collection at Mount Calvert Historical Park, Upper Marlboro, Maryland, USA; ROM, Royal Ontario Museum, Toronto, Ontario, Canada; TMP, Royal Tyrrell Museum of Palaeontology, Drumheller, Alberta, Canada; UCMZ, University of Calgary Museum of Zoology, Calgary, Alberta, Canada; USNM, United States National Museum of Natural History, Washington D.C., USA.

Anatomical Abbreviations: ff, flexor fossa; fo, foramina of flexor fossa; lc; lateral concavity of proximal facet; lg, lateral groove for claw sheath; mc, medial concavity of proximal facet; mg, medial groove for claw sheath; pd, lateral proximal depression; pr, proximodorsal ridge; rc, reconstructed area.

\section{DESCRIPTIONS}

The following description is based primarily on CMN 12068 and CMN 12069 from the Dry Island ornithomimid bonebed in the Tolman Member of the Horseshoe
Canyon Formation (Cullen et al. 2013). These specimens include nearly complete sets of pedal unguals with fully exposed proximal articular facets, permitting rare access to this aspect of their anatomy. Due to their close association in a bonebed, these specimens are interpreted as representing the same species, though a precise taxonomic determination has not been reached (Cullen et al. 2013). Additional supporting observations were taken from the less complete holotypes of Struthiomimus altus Lambe 1902 (CMN 930) from the Belly River Group (Oldman or Dinosaur Park Formation) near Dinosaur Provincial Park, Ornithomimus edmontonicus Sternberg 1933 (CMN 8632) from the Horsethief Member of the Horseshoe Canyon Formation, and Rativates evadens McFeeters et al. 2016 (ROM 1790) from low in the Dinosaur Park Formation. An additional fragmentary ornithomimid specimen, TMP 1991.036.0086 from the Belly River Group of Dinosaur Provincial Park, also preserves pedal unguals II, III, and IV, but none of the proximal facets are complete. Based on this material, the following general description of the positional variation in these ornithomimid pedal unguals can be made.

Pedal ungual II (Fig. 1) is relatively large and distally elongate, with the flexor fossa restricted to the proximal half of the total length. The proximal facet is asymmetrical, with a medial concavity that is larger than the lateral concavity. These concavities are separated by a faint subvertical ridge that leans slightly laterally at its dorsal end, forming an approximately $80-85^{\circ}$ angle with the plantar surface of the ungual. The proximal facet is taller than wide (and taller than the proximal facet of ungual III or IV from the same individual), and varies in shape among the specimens in this sample (for example, being relatively narrow and straightsided in CMN 930, versus proportionately broader and more rounded in CMN 8632). The proximoventral edge is nearly straight in ventral view. In ventral view, the ungual is asymmetrical, with the angle between the proximoventral edge and the ventromedial keel being more nearly perpendicular than the angle between the proximoventral edge and the ventrolateral keel. As a result, the spur formed by the proximal termination of the ventrolateral keel may appear more prominent in ventral view that of the ventromedial keel. The groove for the claw sheath is to some degree more pronounced on the lateral side (strongly asymmetrical in TMP 1991.036.0086, but much less so in CMN 930), and a small, roughened depression is sometimes observed on only the lateral side proximal to the groove (CMN 930, CMN 12069). In CMN 12069, the ventromedial edge is sharper than the ventrolateral edge, but this is not apparent when both edges are well rounded, as in CMN 930.

Pedal ungual III (Fig. 2) is also elongate, but slightly smaller than pedal ungual II of the same individual. The 

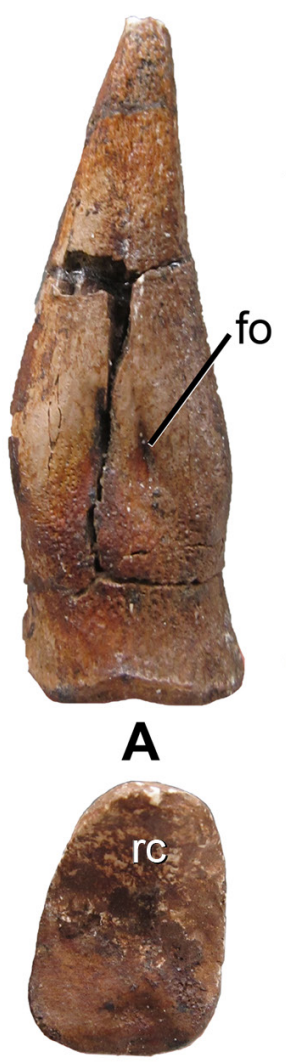

B

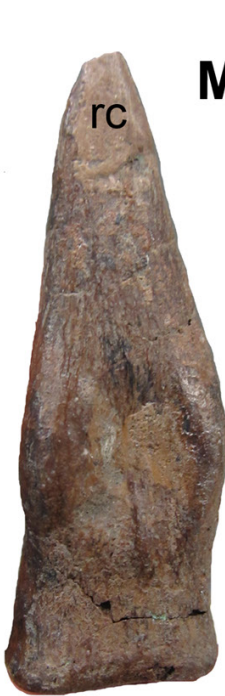

C

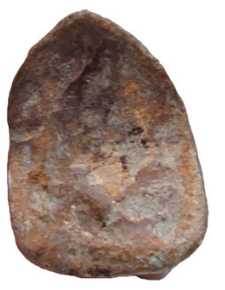

D
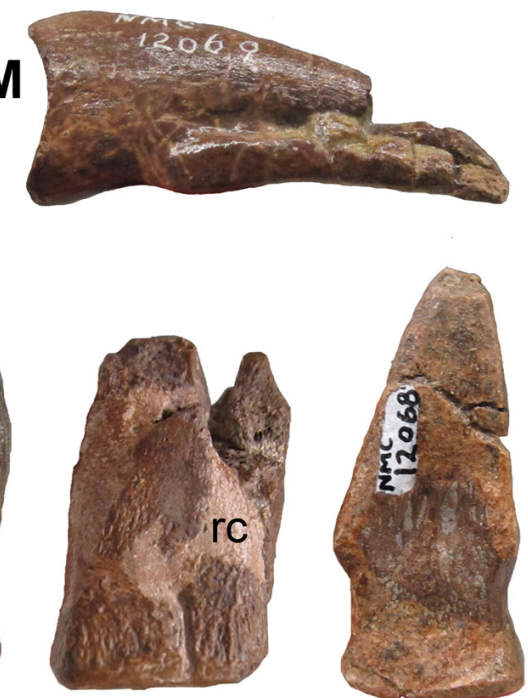

E

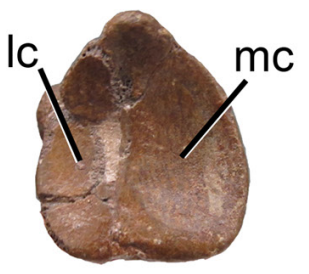

$\mathbf{F}$

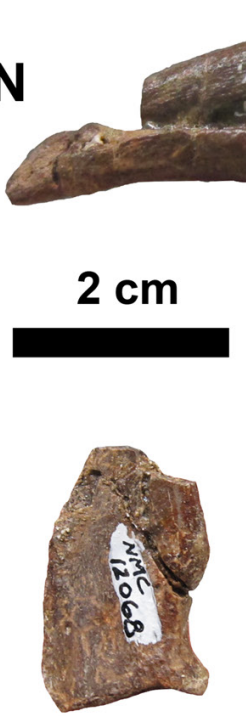

I

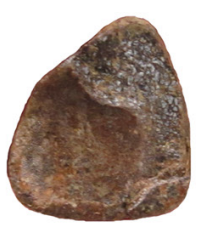

H

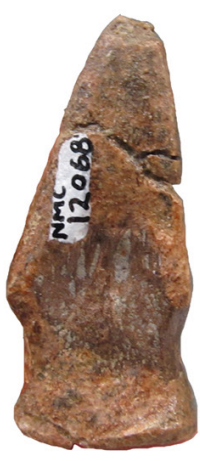

G

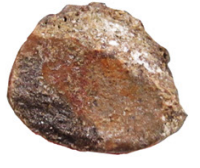

J
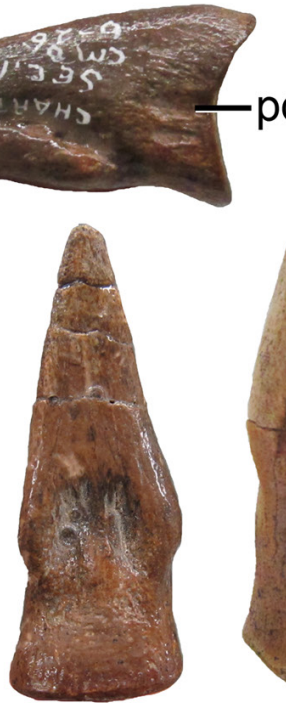

K

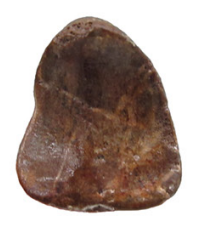

$\mathbf{L}$

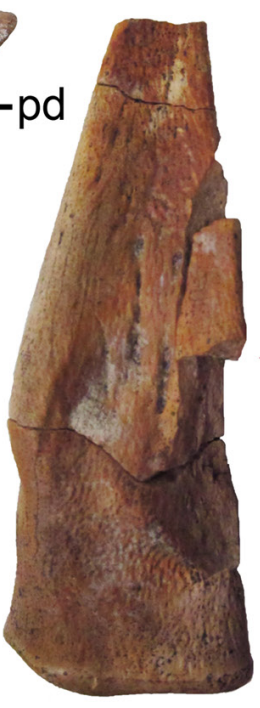

0

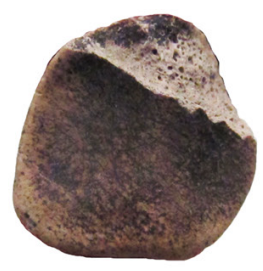

$\mathbf{P}$

Figure 1. Pedal ungual II of ornithomimids: Right pedal ungual II of CMN 930 (holotype of Struthiomimus altus) in A, ventral and B, proximal views. Left pedal ungual II of CMN 930 in C, ventral and D, proximal views. Left pedal ungual II of CMN 8632 (holotype of Ornithomimus edmontonicus) in E, ventral and F, proximal views. Right pedal ungual II of CMN 12068 (Dry Island ornithomimid) in G, ventral and H, proximal views. Left pedal ungual II of CMN 12068 in I, ventral and J, proximal views. Left pedal ungual II of CMN 12069 (Dry Island ornithomimid) in K, ventral, L, proximal, M, medial, and N, lateral views. Right pedal ungual of TMP 1991.036.0086 in O, ventral and P, proximal views.

proximal facet is nearly symmetrical, and is approximately as tall as wide, with the maximum width occurring in the ventral half. The lateral and medial concavities are approximately equal in size, separated by an approximately vertical median ridge. In ventral view, the proximoventral edge is straight with rounded medial and lateral corners. The ventral outline is symmetrical, approximating an isosceles triangle distal to the ventral spurs, with the ventromedial and ventrolateral keels converging distally on the midline. The distance between the ventral spurs and the proximal end is proportionately greater than in ungual II. In contrast with ungual II, the lateral and medial grooves for the claw sheath are equally developed. Proximal to the grooves, dorsolateral and dorsomedial depressions are present on either side of the midline dorsal ridge. Due to the generally symmetrical features of pedal ungual III, it may not be possible to determine whether an isolated specimen belongs to a left pes or a right pes.

Pedal ungual IV (Fig. 3) is in some of its features a mirror image of pedal ungual II, but is smaller and less elon- gate, with the portion distal to the flexor fossa typically not exceeding half of the ungual length. The asymmetrical, subtriangular proximal facet is typically slightly taller than wide, but similar in height to that of ungual III. The larger lateral concavity of the proximal facet is separated from the smaller medial concavity by a ridge that meets the plantar surface at an approximately $70-75^{\circ}$ angle. The proximal facet is skewed medially, such that the ventral edge of the facet is at an oblique angle to the flattened ventral surface of this element, and the proximodorsal process is approximately dorsal to the ventromedial corner. The proximoventral edge is approximately straight in ventral view, except for the more strongly offset ventromedial corner related to the skewed proximal facet. The ventral outline is asymmetrical, with the angle between the proximoventral edge and the ventrolateral keel being more nearly perpendicular than the angle between the proximoventral edge and the ventromedial keel. Related to the less elongate morphology, the angle between the ventrolateral and ventromedial keels is typically ap- 


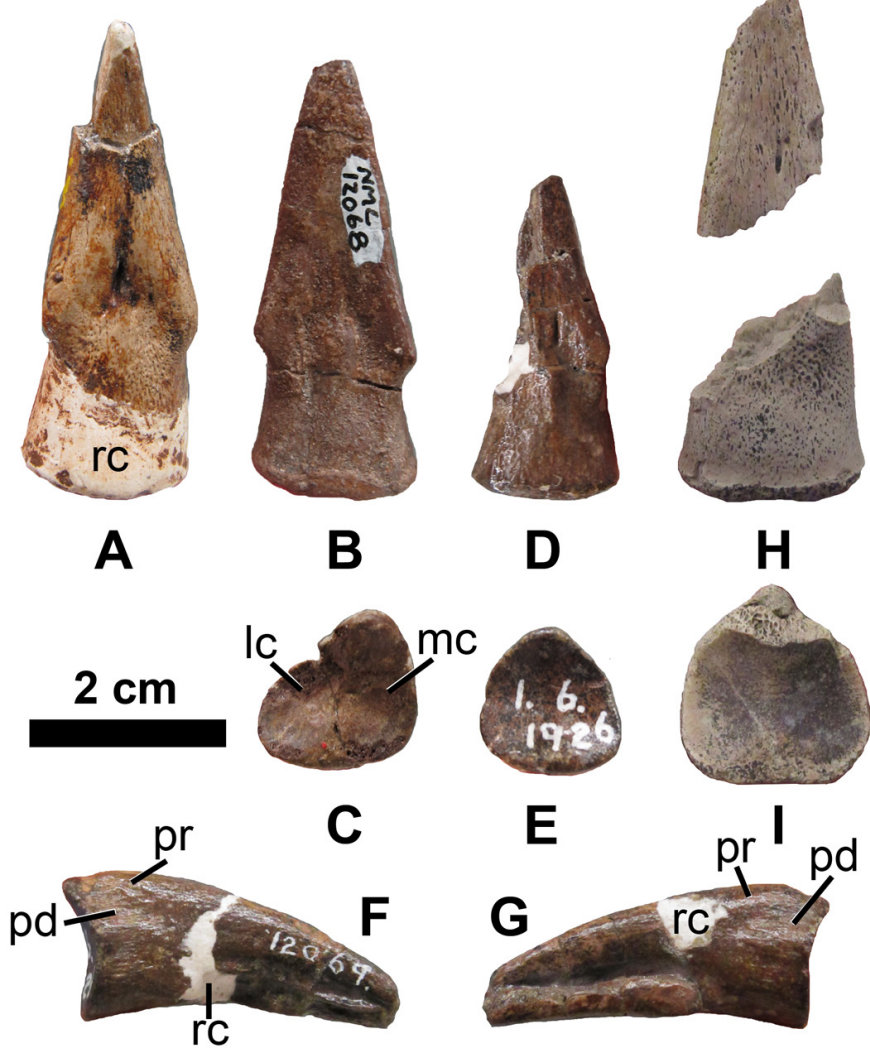

Figure 2. Pedal ungual III of ornithomimids: Right pedal ungual III of CMN 930 (holotype of Struthiomimus altus) in $A$, ventral view (proximal end not preserved). Left? pedal ungual III of CMN 12068 (Dry Island ornithomimid) in B, ventral and C, proximal views. Left? pedal ungual III of CMN 12069 (Dry Island ornithomimid) in D, ventral, E, proximal, F, medial, and G, lateral views. Pedal ungual III of TMP 1991.036.0086 in H, ventral and I, proximal views.

proximately $30^{\circ}$, versus approximately $25^{\circ}$ in unguals II and III. In dorsal view, the dorsal ridge is variably curved laterally (most prominently in CMN 12069, and more subtly in CMN 930). The groove for the claw sheath is deeper on the medial side, where it is more fully enclosed in cross-section by the overhanging medial wall of the ungual (Fig. 3P). A small, roughened depression is sometimes observed on the medial side proximal to the groove. In CMN 12069 and CMN 8632 the ventromedial edge is more rounded than the ventrolateral edge, whereas in CMN 930 both are rounded.

Positional variation in ornithomimosaur pedal ungual morphology as described above is summarized in Table 1 . Characters identified as positionally diagnostic are related to the shape of the proximal facet, the relative size and elongation of the ungual, and the symmetry or asymmetry of morphological features, whereas positionally diagnostic variation was not consistently observed in the dorsoventral curvature of the ungual, the development of the proximodorsal process, or the form of the flexor fossa or flexor tubercle. In CMN 930, the flexor fossa of the left pedal ungual II is shallow and lacks obvious foramina or striations, whereas these features are visible on the right pedal ungual II, suggesting that they are easily masked by poor preservation. On the basis of the above comparisons, we revise the identification of some elements of the Dry Island ornithomimid (Cullen et al. 2013). The element figured by Cullen et al. (2013: fig. 2c) as the right pedal ungual III of CMN 12068 is actually the right pedal ungual II, on the basis of its asymmetrical shape matching pedal ungual II of other specimens (Fig. 1G-H). The left pedal ungual II of CMN 12068 may be represented by a weathered proximal fragment (Fig. 1I-J), which was not figured by Cullen et al. (2013). Although the element figured by Cullen et al. (2013: fig. 2c) as the left pedal ungual III of CMN 12068 appears to possess an asymmetrical proximal facet, this is due to the partial collapse of the bone in this region. Nevertheless, the lateral and medial concavities on the proximal facet are of approximately equal width, and the overall ventral outline is symmetrical, confirming its original identification as ungual III (Fig. 2C). The element figured by Cullen et al. (2013: fig. 3e) as the partial right pedal ungual III of CMN 12069 is more likely a partial left pedal ungual IV (Fig. 3I), possibly belonging to CMN 12068 (no catalogue number is directly associated with it), on the basis of its asymmetrical shape, abbreviated proportions, flexor fossa and ventral spurs located close to the projected distal tip of the ungual, and the relatively large angle between ventrolateral and ventromedial edges.

\section{COMMENTS ON BROWNSTEIN (2017)}

Brownstein (2017) recently described isolated ornithomimosaur postcranial elements collected from the Early Cretaceous Arundel Clay of Maryland. He identified NHRD-AP 2014.s.195, NHRD-AP 2014.s.197, NHRDAP 2014.s.198, NHRD-AP 2016.v.1104, and USNM PAL 529423 as ornithomimosaur pedal unguals based on the presence of a flexor fossa and relatively straight ventromedial edges forming keels, although in some of these specimens he could not confirm both characters (Brownstein 2017: 7). Following Choiniere et al. (2012), he considered pedal unguals with a flat ventral surface and a flexor fossa to occur uniquely in ornithomimosaurs, but these characters also occur in a large theropod pedal ungual referred to the spinosaurid Sigilmassasaurus brevicollis by Novas et al. (2005). Brownstein (2017:7) cited a "triangular shape in proximal view" as additional support for the referral of NHRD-AP 2014.s.197, NHRD-AP 2014.s.198, and NHRD-AP 2016.v.1104 to Ornithomimosauria, claiming that this character was considered a synapomorphy of Ornithomimidae by Barsbold and Osmólska (1990). 

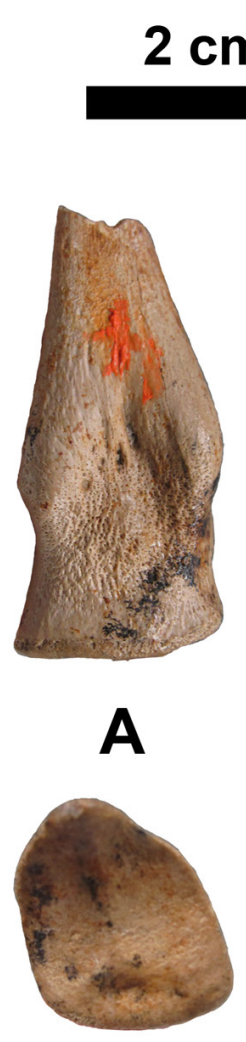

B

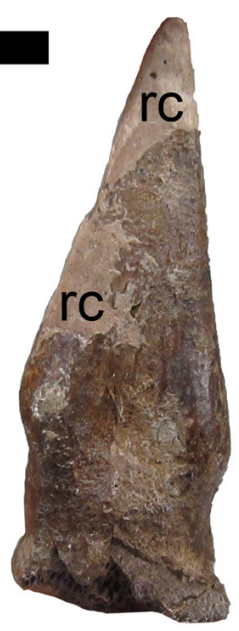

C

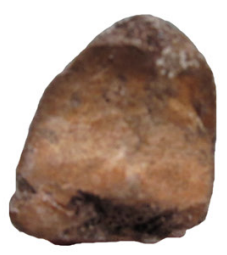

D
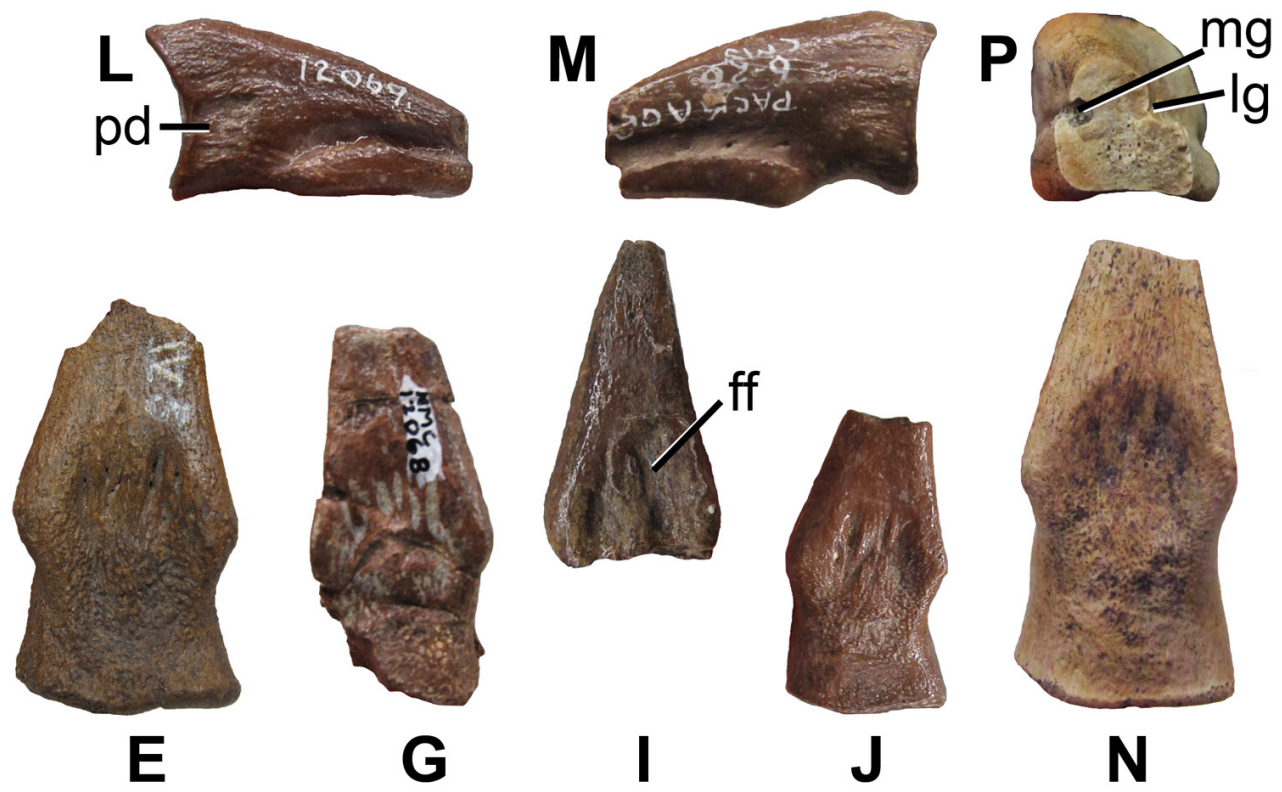

G
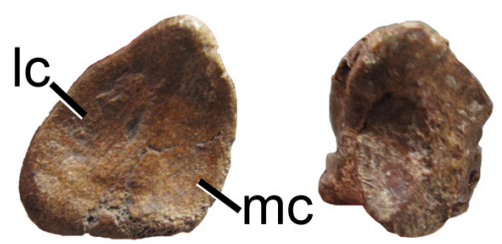

$\mathbf{F}$

H
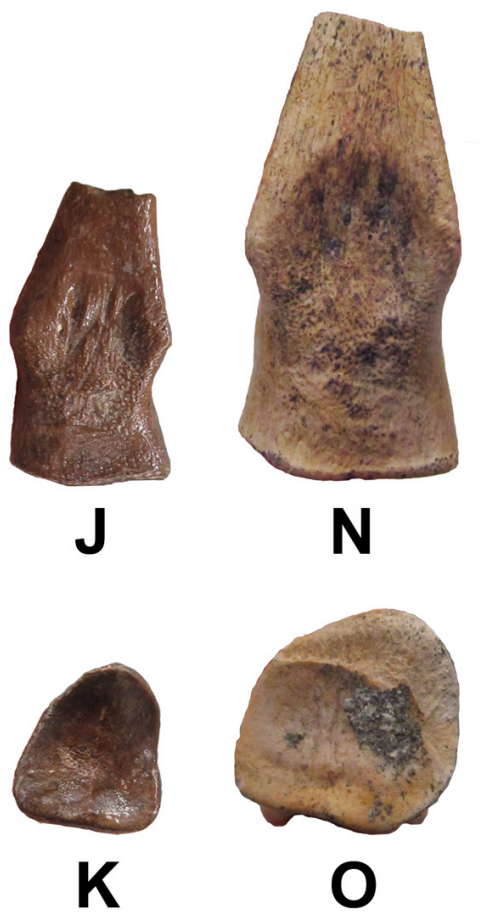

O

Figure 3. Pedal ungual IV of ornithomimids: Right pedal ungual IV of CMN 930 (holotype of Struthiomimus altus) in A, ventral and B, proximal views. Left pedal ungual IV of CMN 930 in C, ventral and D, proximal views. Left pedal ungual IV of CMN 8632 (holotype of Ornithomimus edmontonicus) in E, ventral and F, proximal views. Right pedal ungual IV of CMN 12068 (Dry Island ornithomimid) in G, ventral and $\mathrm{H}$, proximal views. Left pedal ungual IV of CMN 12068(?) in I, ventral view (proximal end not preserved). Left pedal ungual of CMN 12069 in J,ventral, K, proximal, L, medial, and M, lateral views. Left pedal ungual of TMP 1991.036.0086 in N, ventral, O, proximal, and P, distal cross-sectional views.

However, no such character actually appears in their diagnosis of that taxon (Barsbold and Osmólska 1990:239); this character is positionally dependent in the Albertan ornithomimids observed in this study (Table 1).

Nevertheless, we tentatively accept an ornithomimosaurian identification for the pedal unguals described by Brownstein (2017), as it is consistent with the size and overall morphology of these elements. This identification is further supported by the presence of other potentially ornithomimosaurian material in the Arundel Clay (Gilmore 1920; Brownstein 2017). However, we point out that this identification may require future revision or refinement with the recovery of additional Arundel Clay theropod material, given the homoplastic distribution of traditionally ornithomimosaurian pedal ungual characters (such as reduced ungual recurvature, flat ventral surfaces, and presence of a flexor fossa) among other Cretaceous theropods including spinosaurids (Novas et al. 2005; Ibrahim et al. 2014), noasaurids (Sereno 2017), and Gualicho shinyae (Apesteguía et al. 2016).
Although Brownstein (2017) considered most of the unguals he observed to be ornithomimosaur pedal unguals, he identified one element (NHRD-AP 2014.s.196), which he considered to represent a distinct morphotype, as a manual ungual of a more derived ornithomimosaur based on its ventrally flattened shape and absence of a flexor tubercle. $\mathrm{He}$ argued that these features allied this specimen with derived ornithomimosaurs such as Gallimimus. However, a distinct flexor tubercle is present on all known ornithomimosaur manual unguals, including those of Gallimimus bullatus (Osmólska et al. 1972:fig. 14). It is therefore unlikely that NHRD-AP 2014.s.196, which lacks this structure, represents an ornithomimosaur manual ungual. Brownstein (2017:11) explicitly rejected positional variation to explain the differences between the two ungual morphotypes that were recognized from the Arundel Clay, claiming that in "ornithomimosaurs where the proximal faces of more than one pedal ungual is exposed and documented (e.g., Beishanlong grandis, Rativites [sic] evadens, Struthiomimus altus, Ornithomimus edmonticus [sic], and 
Table 1. Generalized description of positional variation in ornithomimid pedal unguals.

\begin{tabular}{|c|c|c|c|}
\hline Attribute & Pedal Ungual II & Pedal Ungual III & Pedal Ungual IV \\
\hline Outline of proximal facet & Asymmetrical, taller than wide & Approximately symmetrical & Asymmetrical, subtriangular \\
\hline $\begin{array}{l}\text { Medial concavity on } \\
\text { proximal facet }\end{array}$ & Larger than lateral concavity & $\begin{array}{l}\text { Approximately equal to lateral } \\
\text { concavity }\end{array}$ & Smaller than lateral concavity \\
\hline Outline in ventral view & Asymmetrical, elongate & Approximately symmetrical & Asymmetrical, abbreviated \\
\hline $\begin{array}{l}\text { Angle between ventro- } \\
\text { medial and ventrolateral } \\
\text { edges }\end{array}$ & $-25^{\circ}$ & $-25^{\circ}$ & $-30^{\circ}$ \\
\hline
\end{tabular}

Gallimimus bullatus), all pedal unguals are flattened or slightly recurved to a similar degree and share a distinct triangular shape in cross-section (Makovicky, Kobayashi \& Currie, 2004; Makovicky et al., 2009; McFeeters et al., 2016)." However, Makovicky et al. (2004) did not document the detailed pedal ungual morphology of any specific ornithomimosaur taxon in a manner that would allow positional variation in proximal facet shape, curvature, or cross section to be assessed. Makovicky et al. (2009:fig. 3) figured three pedal unguals of Beishanlong grandis, but did not document their shapes in proximal view, and pedal ungual III is not represented. McFeeters et al. (2016:fig. 11) figured three incomplete pedal unguals of Rativates evadens, but of these, only one (pedal ungual II) has a complete proximal articular facet, another preserves a portion of this facet (pedal ungual IV), and the other does not preserve it at all (pedal ungual III). The type specimens of Struthiomimus altus (CMN 930) and Ornithomimus edmontonicus (CMN 8632) also lack a preserved proximal facet for pedal ungual III, while the proximal views of their pedal unguals II and IV have not been figured. In other specimens referred to these taxa with multiple pedal unguals preserved (e.g., AMNH 5339, ROM 851, UCMZ 1980.1), the precise shapes and details of the proximal facets cannot be readily documented due to the pedal phalanges being mounted in articulation. Osmólska et al. (1972:fig. 17, pl. 49) figured two specimens of G. bullatus with multiple pedal unguals preserved, but also did not document the shapes of the proximal facets.

Brownstein (2017) also claimed that the differences between the two morphotypes do not represent positional variation because positional variation can be recognized within the morphotype interpreted as the more basal ornithomimosaur taxon in this assemblage. According to Brownstein (2017:11), USNM V 6107 (co-type of Ornithomimus affinis; Gilmore 1920) is "straightened" in ventral view, suggesting its identity to be pedal ungual III. However, it is evident from published figures (SerranoBrañas et al. 2016:fig. 8) that USNM V 6107 is asymmetrical in ventral view, similar to other pedal unguals assigned to the blunt ungual morphotype.

Non-ungual material referred to Ornithomimosauria by Brownstein (2017) includes the proximal and distal ends of a humerus (NHRD-AP 2015.v.103.9) and a caudal vertebra (NHRD-AP 2016.5.503). Brownstein (2017) suggested that the relatively thick humerus supports the presence of a basal ornithomimosaur, similar to Harpymimus okladnikovi, in this assemblage. However, as the total length of the humerus cannot be established, it is impossible draw any firm conclusions regarding the robustness of this element as conventionally quantified in phylogenetic analyses of Ornithomimosauria (Kobayashi and Lü 2003: character 24).

In summary, we conclude that there is no compelling evidence for the presence of two distinct ornithomimosaur taxa in the Arundel Clay of Maryland.

\section{DISCUSSION AND CONCLUSIONS}

A review of pedal anatomy of multiple ornithomimosaur taxa from the late Campanian-early Maastrichtian of Alberta reveals a consistent pattern of pedal ungual positional variation. Although our sample is too small to assess quantitatively the effects of individual variation on 
ungual morphology, this variation is consistent with that independently documented in another ornithomimid taxon from the Campanian of Mongolia (Tsogtbaatar et al. 2017). Among Early Cretaceous basal ornithomimosaurs, the pedal unguals are most completely represented in Nedcolbertia justinhofmanni (Kirkland et al. 1998), Nqwebasaurus thwazi (Choiniere et al. 2012, Sereno 2017), and Hexing qingyi (Jin et al. 2012). Comparative data on positional variation is presently limited in that none of these taxa has multiple pedal unguals figured in proximal or ventral views. However, given the strong similarity in the ventrally flattened form of the pedal unguals, and that the asymmetrical morphology of pedal ungual IV in N. thwazi (Choiniere et al. 2012:fig. 14 ) is essentially consistent with the homologous position in ornithomimids, we believe that our criteria for positional assignment can tentatively be accepted for ornithomimosaurs in general. These observations suggest that, if positional variation is not taken into consideration, taxonomic distinctions on the basis of pedal ungual morphology could be erroneous. For example, the figured pedal unguals chosen by Longrich (2008:fig. 12) to represent Ornithomimus sp. and Struthiomimus sedens are both the left pedal ungual II, but the element figured to represent $S$. altus appears to be a pedal ungual III. Thus the figure overemphasizes the morphological difference between $S$. altus and the other taxa, and could create the mistaken impression that other isolated examples of pedal ungual III from the Campanian of Alberta compare most favourably with $S$. altus, regardless of their actual taxonomic origin.

Positional variation similar to that observed in the Albertan ornithomimids can be recognized in the Arundel Clay pedal unguals referred to ornithomimosaurs by Brownstein (2017). The "blunt morphotype" represented by NHRD-AP 2014.s.197, NHRD-AP 2014.s.198, NHRD-AP 2016.v.1104, and USNM V 6107 (Brownstein 2017:11), and interpreted by Brownstein (2017) as representing a relatively basal ornithomimosaur, corresponds to the marginal pedal unguals (unguals II and IV) on the basis of the subtriangular, asymmetrical proximal facet, unequally developed claw sheath grooves, an asymmetrical outline in ventral view, and in some specimens (corresponding to ungual IV), abbreviated proportions and weak lateral curvature. The morphotype represented by NHRDAP 2014.s. 195 and USNM PAL 529423, interpreted by Brownstein (2017) as representing a relatively derived ornithomimosaur, corresponds to pedal ungual III, on the basis of the broad, approximately symmetrical proximal facet, symmetrically developed proximal depressions that contribute to defining the proximodorsal ridge, strongly developed claw sheath grooves on both sides, and a relatively elongate and symmetrical outline in ventral view. A significant difference in dorsoventral curvature is not apparent between the two morphotypes figured by Brownstein (2017), and we regard the described differences between the flexor fossae as potentially preservational. Thus, we see no reason that these two pedal ungual morphotypes could not represent a single ornithomimosaur taxon, contra Brownstein (2017, 2018), and favour this as the most parsimonious interpretation. Although the sample size is unfortunately too low to exclude coincidence, the number of specimens assigned to each morphotype by Brownstein (2017) is proportional to the numbers of central and marginal pedal unguals in a single ornithomimosaur individual (if pedal digit $\mathrm{I}$ is assumed to be absent), as would be expected in a random sampling of isolated unguals from a single taxon. Brownstein $(2017 ; 2018)$ suggested that the co-occurrence of relatively basal and relatively derived ornithomimosaurs in the Arundel Clay makes this assemblage similar to the Yixian Formation of China. However, the two Yixian ornithomimosaurs, Shenzhousaurus orientalis and Hexing qingyi, are both plesiomorphic in their possession of dentary teeth (Ji et al. 2003; Jin et al. 2012), and are recovered together in a polytomy near the base of Ornithomimosauria in the phylogenetic analysis by Jin et al. (2012). Thus, the Yixian Formation appears to lack "derived ornithomimosaurs." If the Arundel Clay material does, indeed, represent a single ornithomimosaur taxon (Gilmore 1920), then there is no physical evidence supporting the co-occurrence of relatively basal ornithomimosaurs and more derived ornithomimosaurs (i.e., members of the unnamed Deinocheiridae + Ornithomimidae clade) at any known fossil locality. However, the oldest fossils suggested to be derived ornithomimosaurs (e.g., Kinnareemimus khonkaenensis; Buffetaut et al. 2009) likely overlap in time with the fossil record of basal ornithomimosaurs, suggesting that such a co-occurrence could be found in the future. Buffetaut et al. (2009) suggested that the co-types of Ornithomimus affinis may represent a member of the relatively derived clade, based on the morphology of a partial third metatarsal (USNM 5684), but this has not been tested in a published phylogenetic analysis. More information is needed to establish the phylogenetic position of the Arundel Clay material in relation to better-known ornithomimosaurs, the global pattern of replacement of basal ornithomimosaurs by derived ornithomimids and deinocheirids, and the origins of multi-taxic ornithomimosaur assemblages in North America.

\section{ACKNOWLEDGEMENTS}

We thank Margaret Currie, Jordan Mallon, and Kieran Shepherd at the CMN, David Evans, Brian Iwama, and Kevin Seymour at the ROM, and Don Brinkman and Brandon Strilisky at the TMP for assistance during collection visits. Robert Holmes, Alexander Dececchi, and an anonymous reviewer provided constructive criticism of an earlier draft of this paper. 


\section{LITERATURE CITED}

Apesteguía, S., N.D. Smith, R. Juárez Valieri, and P.J. Makovicky. 2016. An unusual new theropod with a didactyl manus from the Upper Cretaceous of Patagonia, Argentina. PLoS One 11: e0157793, 1-41.

Barsbold, R., and H. Osmólska. 1990. Ornithomimosauria; pp. 225-244 in D. B. Weishampel, P. Dodson, and H. Osmólska (eds.), The Dinosauria. University of California Press, Berkeley, California.

Brownstein, C.D. 2017. Description of Arundel Clay ornithomimosaur material and a reinterpretation of Nedcolbertia justinhofmanni as an "Ostrich Dinosaur": biogeographic implications. PeerJ 5:e3110, 1-20.

Brownstein, C.D. 2018. The biogeography and ecology of the Cretaceous non-avian dinosaurs of Appalachia. Palaeontologia Electronica 21.1.5A:1-56.

Buffetaut, E., V. Suteethorn, and H. Tong. 2009. An early 'ostrich dinosaur' (Theropoda: Ornithomimosauria) from the Early Cretaceous Sao Khua Formation of NE Thailand. The Geological Society, London, Special Publications 315:229-243.

Choiniere, J.N., C.A. Forster, and W.J. de Klerk. 2012. New information on Nqwebasaurus thwazi, a coelurosaurian theropod from the Early Cretaceous Kirkwood Formation in South Africa. Journal of African Earth Sciences 71-72:1-17.

Cullen, T.M., M.J. Ryan, C. Schröder-Adams, P.J. Currie, and Y. Kobayashi. 2013. An ornithomimid (Dinosauria) bonebed from the Late Cretaceous of Alberta, with implications for the behavior, classification, and stratigraphy of North American ornithomimids. PLoS One, 8:e58853, 1-9.

Gilmore, C.W. 1920. Osteology of the carnivorous Dinosauria in the United States National Museum, with special reference to the genera Antrodemus (Allosaurus) and Ceratosaurus. United States National Museum Bulletin 110:1-154.

Hunt, R.K. and J.H. Quinn. 2018. A new ornithomimosaur from the Lower Cretaceous Trinity Group of Arkansas. Journal of Vertebrate Paleontology 38:e1421209, 1-12.

Ibrahim, N., P.C. Sereno, C. Dal Sasso, S. Maganuco, M. Fabbri, D.M. Martill, S. Zouhri, N. Myhrvold, and D.A. Iurino. 2014. Semiaquatic adaptations in a giant predatory dinosaur. Science 345:1613-1616.

Ji, Q., M.A. Norell, P.J. Makovicky, K.-Q. Gao, S. Ji, and C. Yuan. 2003. An early ostrich dinosaur and implications for ornithomimosaur phylogeny. American Museum Novitates 3420:1-19.

Jin, L., J. Chen, and P. Godefroit. 2012. A new basal ornithomimosaur (Dinosauria: Theropoda) from the Early Cretaceous Yixian Formation, northeast China; pp. 466-487 in P. Godefroit (ed.), Bernissart Dinosaurs and Early Cretaceous Terrestrial Ecosystems. Indiana University Press, Bloomington, Indiana.

Kirkland, J. I., B.B. Britt, C.H. Whittle, S.K. Madsen, and D.L. Burge. 1998. A small coelurosaurian theropod from the Yellow Cat Member of the Cedar Mountain Formation (Lower Cretaceous, Barremian) of eastern Utah. New Mexico Museum of Natural History and Science Bulletin 14:239-248.
Kobayashi, Y., and J.-C. Lü. 2003. A new ornithomimid dinosaur with gregarious habits from the Late Cretaceous of China. Acta Palaeontologica Polonica 48:235-259.

Lambe, L.M. 1902. New genera and species from the Belly River Series (mid-Cretaceous). Geological Survey of Canada, Contributions to Canadian Paleontology 3:25-81.

Longrich, N.R. 2008. A new, large ornithomimid from the Cretaceous Dinosaur Park Formation of Alberta, Canada: implications for the study of dissociated dinosaur remains. Palaeontology 51:983-997.

Makovicky, P. J., Y. Kobayashi, and P.J. Currie. 2004. Ornithomimosauria; pp. 137-150 in D. B. Weishampel, P. Dodson, and H. Osmólska (eds.), The Dinosauria, Second Edition. University of California Press, Berkeley, California.

Makovicky, P. J., D. Li, K.-Q. Gao, M. Lewin, G.M. Erickson, and M.A. Norell. 2009. A giant ornithomimosaur from the Early Cretaceous of China. Proceedings of the Royal Society B 277:191-198.

McFeeters, B., M.J. Ryan, C. Schröder-Adams, and T.M. Cullen. 2016. A new ornithomimid theropod from the Dinosaur Park Formation of Alberta, Canada. Journal of Vertebrate Paleontology 36:e1221415, 1-20.

Novas, F.E., F. Dalla Vecchia, and D.F. Pais. 2005. Theropod pedal unguals from the Late Cretaceous (Cenomanian) of Morocco, Africa. Revista del Museo Argentino de Ciencias Naturales, Nueva Serie 7:167-175.

Osmólska, H., E. Roniewicz, and R. Barsbold. 1972. A new dinosaur, Gallimimus bullatus n. gen., n. sp. (Ornithomimidae) from the Upper Cretaceous of Mongolia. Palaeontologia Polonica 27:103-143.

Schwimmer, D.R., A.E. Sanders, B.R. Erickson, and R.E. Weems. 2015. A Late Cretaceous dinosaur and reptile assemblage from South Carolina, USA. Transactions of the American Philosophical Society 105 (2):1-157.

Sereno, P.C. 2017. Early Cretaceous ornithomimosaurs (Dinosauria: Coelurosauria) from Africa. Ameghiniana 54:576-616.

Serrano-Brañas, C.I., E. Torres-Rodríguez, P.C. Reyes-Luna, I. González-Ramírez, and C. González-León. 2016. A new ornithomimid dinosaur from the Upper Cretaceous Packard Shale Formation (Cabullona Group) Sonora, México. Cretaceous Research 58:49-62.

Sternberg, C.M. 1933. A new Ornithomimus with complete abdominal cuirass. Canadian Field-Naturalist 47:79-83.

Tsogtbaatar, C., Y. Kobayashi, T. Khishigjav, P.J. Currie, M. Watabe, and B. Rinchen. 2017. First ornithomimid (Theropoda, Ornithomimosauria) from the Upper Cretaceous Djadokhta Formation of Tögrögiin Shiree, Mongolia. Scientific Reports 7:5835, 1-14. 